\title{
The Contribution of BMS Application Towards the Sustainability and Life Cycle Costs Optimization of Buildings: A Case of Public Utility Facilities in Poland
}

\author{
Krystyna Araszkiewicz ${ }^{1}$, Patrycja Jakubowska ${ }^{1}$ and Saurav Dixit ${ }^{2}$ \\ 1 West Pomeranian University of Technology, Szczecin, Poland, krystyna.araszkiewicz@zut.edu.pl, \\ patrycja.jakubowska@zut.edu.pl \\ 2 RICS School of Built Environment, Amity University Noida, India
}

\begin{abstract}
BMS (Building Management System), i.e. the central building control, assumes integrated control of all building functions - from air conditioning and heating to lighting, access control and security issues. Properly designed BMS solutions improve the operation of the building service, allow for a quick reaction in case of emergency situations and significantly facilitate maintenance activities. Building automation systems also allow for data collection and analysis, which can be used among other things, to optimise energy and water consumption in buildings.

The aim of the paper is to provide and to discuss findings of the analysis of the impact of the BMS application in the city stadium design, which is an example of a public facility, on the possibility of controlling the life cycle costs of the facility under examination.

In the first step, on the basis of the design documentation and the stadium operation schedule prepared by the authors, the life cycle costs of the analysed facility were calculated in accordance with the methodology recommended by the Polish public procurement law with use of the SMART SPP calculation tool. The functional assumptions of the BMS designed for the stadium were taken into account. Then a change was introduced to the analysis at the input consisting in the simulation of BMS removal from the facility and then the introduction of the risk factor of human error on the part of the staff during the annual operation of the stadium in relation to the operation of the lighting system of the facility. The analysis is summarised by comparing the calculation results for both scenarios. The findings indicate the benefits of using BMS in facility management.
\end{abstract}

(c) 2020 The Authors. Published by Budapest University of Technology and Economics \& Diamond Congress Ltd Peer-review under responsibility of the Scientific Committee of the Creative Construction Conference 2020.

Keywords: BMS (building management system), life cycle costs analysis, sustainability, SDG, energy consumption, smart buildings

\section{Introduction}

The construction sector has got a significant unused energy saving potential. According to the Roadmap of Actions planned at the level of the European Union to implement the rules of the low-emission economy in 2050 , it is estimated that emissions from built-up areas could be reduced by about $90 \%$ by 2050 by introducing passive technologies in new buildings, modernisation of old buildings to improve their energy efficiency and replacing fossil fuels with electricity as well as RES in heating and cooling systems [1]. At the beginning of June 2018, the Directive 2018/844 of the European Parliament and of the Council (EU) of 30 May 2018 amending the Directive 2010/31/EU on the energy performance of buildings and the Directive 
2012/27/EU on energy efficiency was published. The new legislation entered into force on 9 July 2018 and the EU Member States had 20 months from the date of entry into force to transpose the Directive into their legal systems. The deadline was on 10 March 2020. In accordance with the Directive 2018/844, the Member States were obliged to establish a long-term strategy to support the renovation of the existing resources of residential and non-residential buildings, including both public and private, in order to achieve high energy efficiency equivalent to nearly zero energy consumption buildings by 2050 . New buildings must meet two conditions at the same time: firstly, it is a condition of adequate insulation of the building external partitions and secondly, a condition of annual primary non-renewable energy demand below values specified by the Directive.

The energy efficiency of a building is determined primarily by three elements - well insulated external partitions and joinery with appropriate parameters, a source of heat and cold and the possibility of optimising energy flows in the building's technical systems [2]. Ensuring optimal operating parameters of individual systems is the main function of automatic control and regulation systems, i.e. automation as well as control and measurement equipment. Modern buildings contain many technical systems, and this requires integration and coordination of their operation. This task is to be met by BMS systems (Building Management Systems) [3,4,5].

An analytical tool integrating the issues of environmental efficiency, including energy and economic issues is the Life Cycle Cost Analysis (LCCA). The concept of a building's life cycle is comprehensively defined in the ISO 15686-5:2017 standard. The aim of the standard is to disseminate the practical use of the LCCA in the construction industry to support effective planning and control of the costs associated with the operation of different types of buildings, and to support the development of the market practice in the application of the criterion of the cost of the life cycle of buildings in the public procurement.

\section{Method}

The aim of the paper is to provide and to discuss findings of the analysis of the impact of using BMS in the design of a city stadium, which is an example of a public facility, on the possibilities of cost control and energy efficiency during the life cycle of the examined facility.

First of all, on the basis of the design documentation and the schedule of the stadium's operation over 25 years, the costs of the life cycle of the analysed facility were calculated in accordance with the methodology recommended by ISO 15686-5:2017 and the Polish public procurement law. The first year of construction of the facility was assumed to be the base year, i.e. the moment when the life cycle accounting period begins.

The SMART SPP calculation tool was used. The functional assumptions of the BMS, designed for the stadium in question were taken into account. Then a change was introduced to the input assumptions of the analysis consisting in a simulated removal of the BMS from the facility and introduction of a risk factor for human error on the part of manual operation, during the annual operation of the stadium in relation to the operation of the facility lighting system. The analysis is summarised by comparing the results of the calculation for four variant scenarios.

The product life cycle analysis assumes examining potential environmental impacts, from the excavation and transport of raw materials, through the processes of product manufacturing, distribution, operation, reuse of recovered materials, to the management and final disposal of waste. Consequently, the LCCA examines the above mentioned stages of the product life cycle in a modelled approach. Due to the focus of the analysis on the impact of the BMS system on the results of the energy consumption by the examined object's lighting system, a significant limitation has been adopted for the analysis, consisting in the fact that the limits of the product system were determined starting from the purchase of ready-made equipment forming the lighting system. The processes of raw material acquisition and production of these devices are not included here. The analysis is limited to the stage of construction and then use and demolition of the object. This is a significant simplification, but it was introduced due to the purpose of the study. The authors of the ISO 15686-5:2017 standard emphasise that the calculation of life cycle costs of a building facility may 
be of significance at each of its stages, therefore the assumptions made for the study concerned are consistent with the general guidelines of the cited standard.

The presentation of the results of calculations and comparative analysis was preceded by discussing the literature review. It was carried out with the use of Scopus, Web of Sciences and Google Scholar scientific publication databases. In order to obtain relevant articles relating to the problem undertaken in the study, common keywords were adopted including such phrases as "Life Cycle Cost Analysis", "Construction sector", "Building Management Systems". The search was limited to articles published in the last decade, i.e. from 2010 to 2019 inclusive. The total of 30 articles was finally selected to be valid for further analysis.

\section{Results of the literature review}

In modern buildings, in addition to the regulation elements and control of individual technical systems such as heating, air conditioning, lighting, etc. the possibility of controlling the cooperation between the systems is assumed. The integration of control and regulation systems in a building is a basic feature of the BMS $[6,7]$. The aim of using integrated systems is to reduce building operating costs while maintaining proper parameters of the internal environment. Additionally, attention is paid to increased technical safety of the integrated systems, optimal operating parameters of individual systems and easier detection of faults and failures $[8,9]$.

One of the basic functions of automation, which allows to achieve the greatest savings during the operation of the building, is the appropriate control of light and the thermal environment of rooms, while maintaining the requirements in the existing standards and regulations [10]. The basic functionality related to the lighting system is the automatic switch-on/switch-off combined with the lighting intensity control and the so-called light scenes [11]. The lighting control function is often integrated with presence sensors and threshold light intensity sensors. This allows the lighting to be automatically switched on when motion is detected if the natural light is too low and switched off when the room is not used for a longer time. In the BMS lighting systems, a comprehensive solution is most often used, including the possibility of their zoning within the building or rooms [12]. More advanced systems use additional lighting intensity control systems depending on the daylight intensity or operational schedule. An additional function of the system is to monitor the condition of lighting. $[13,14,15,16]$

In the buildings with nearly zero energy consumption, sustainable and equipped with smart technologies, control systems above the standard are often used. These include adaptive regulation that uses information collection and algorithm synthesis based on the current behaviour of a particular system, and fuzzy regulation based on the transformation of information using fuzzy logic $[17,18,19]$. Control algorithms more and more often include modules using neural networks or genetic algorithms, which increase the efficiency of collecting and managing information about the behaviour of the building, system and users. Among the most advanced control systems, which are in the implementation research phase, there is a combined system using both historical data and prediction methods. For controlling in this system, models of building functioning are used, verified on the basis of data from the past, as well as predicted values coming from e.g. weather forecast and forecast of the building use by users [20,21].

The way the BMS is used to optimise the performance of individual technical systems, including lighting, affects cost-effectiveness, as shown, for example, by the research carried out on the basis of a case study of the first zero-energy building in the Southeast Asia, using passive and active BMS strategies [22].

The analyses discussed in the publication [xx] show, inter alia, that energy cost is a weighting of $48 \%$ of a building's total life cycle budget, with this ratio increasing above $60 \%$ when it is only weighted against the building's operating costs [23].

Current BMSs use two-dimensional vector graphics to help facility managers manage their buildings. However, the system is not fully interactive and can only be operated by a trained operator. One of the methods to improve the functioning of the BMS could be to introduce an information-rich BIM model that provides real-time information through the BMS [24,25,26,27]. 
The information on the life cycle of a building must be developed and maintained from the preliminary design to the operation stage. Well defined and available BIM information allows for life cycle analysis at every stage of the project. However, an economic analysis alone is not sufficient, and it is recommended to consider the relationship with the environmental impact [28].

The life-cycle cost assessment (LCCA) of sustainable building designs has been developed for more than a decade and studies show that the use of this analytical technique brings benefits in the decision making process as it can be used to review and assess the concept of sustainable development measures throughout the whole life cycle of a building, including the determination of the carbon footprint, the simultaneous analysis of energy consumption in assessing the environmental performance of buildings and the analysis of the economic efficiency [29,30].

The latest technical standards concerning the LCC issues include the ISO 15686-5:2017 standard, published in July 2017. The LCC according to the standard means "the cost of an asset or a part of it over its entire life cycle while meeting performance requirements: it applies to the UK construction industry and to key stages of the procurement process".

\section{LCCA calculation results}

\subsection{Description of the investment under analysis}

The subject of the analysis is the construction of the Children and Youth Training Centre together with the reconstruction and extension of the football stadium, football pitches and accompanying infrastructure. The capacity of the facility will be about 20500 seats. Four football pitches will be built, including three fullsize and one with an artificial surface reduced by about $10 \%$ in relation to the size of the grass pitch dimensions. In order to achieve optimised control of the technical functions of the building, a building automation and safety system (BMS/SMS) was designed. It was assumed that the designed BMS/SMS would provide a coherent interface for all systems -building automation, fire protection, security systems, including access control, intrusion and robbery alarm system, CCTV. The basic functions of the designed BMS/SMS system included:

- monitoring the operation of selected equipment in the building

- $\quad$ archiving and viewing data

- supporting the facility maintenance services in emergency situations

- controlling the devices in an automatic way.

\subsection{Results of calculations}

The data needed for the LCCA were obtained from the Investor's documentation and from the lighting manufacturer. The annual operation schedule of the stadium was adopted for the analysis in relation to the programme assumptions of the facility with regards to the planned football matches (tab.1).

Table 1. Schedule of the annual operation of the stadium.

\begin{tabular}{|c|c|c|c|c|}
\hline Football matches & $\begin{array}{l}\text { Level of lighting } \\
\text { of the pitch [\%] }\end{array}$ & $\begin{array}{l}\text { Level of lighting } \\
\text { of the pitch [LUX] }\end{array}$ & Match duration [h] & $\begin{array}{l}\text { Number of matches per } \\
\text { year }\end{array}$ \\
\hline Club international matches & $100 \%$ & 2000 & 7 & 3 \\
\hline $\begin{array}{l}\text { National premier league and } \\
\text { league matches }\end{array}$ & $100 \%$ & 2000 & 6 & 20 \\
\hline $\begin{array}{l}\text { National matches of } 3 \text { rd and } \\
\text { 4th leagues }\end{array}$ & $50 \%$ & 1000 & 3 & 15 \\
\hline $\begin{array}{l}\text { Children and youth club and } \\
\text { training matches }\end{array}$ & $20 \%$ & 500 & 2 & 300 \\
\hline
\end{tabular}

The lighting of the pitch according to the construction design consists of 196 lamps suspended from the roof structure of the stadium. 
Four optional scenarios were adopted for the analysis (tab.2):

S.1 The lighting of the pitch is controlled automatically by the BMS system,

S.2 The lighting of the pitch is controlled manually. This variant takes into account the human error of mistakenly failing to switch off the lighting at a certain time - as a consequence, the lighting time is extended by $1 \mathrm{~h}$ in case of each planned match (taking into account the time needed to get to the control point),

S.3 The lighting of the pitch is controlled manually. This variant takes into account the human error of setting the level of lighting higher than assumed and than necessary in the national matches of 3rd and 4th leagues, children and youth club and training matches,

S.4 The lighting of the pitch is controlled manually. This variant takes into account the human error of leaving the lighting on at night in 1/3 of the number of all matches - as a consequence, the lighting operation time is extended by an additional 12 hours.

Table 2.

\begin{tabular}{lccr}
\hline The lighting of the pitch - scenario & Total time in [h] & $\begin{array}{l}\text { Quantity } \\
\text { kWh/h 1 lamp }\end{array}$ & $\begin{array}{c}\text { of } \\
\text { Total quantity } \\
\text { of kWh }\end{array}$ \\
\hline Scenario 1 (S.1) & 786 & 0.57 & 87867.78 \\
Scenario 2 (S.2) & 1124 & 0.53 & 117437.32 \\
Scenario 3 (S.3) & 786 & 1.43 & 220300.08 \\
Scenario 4 (S.4) & 2130 & 0.49 & 203903.70 \\
\hline
\end{tabular}

The analysis was carried out for the period of 25 years, and a discount rate of $3 \%$ was assumed. The results presenting the life cycle costs were obtained in the annual and summary approach for the lighting system with the assumption of four variants of controlling of the system (tab.3). The share of particular costs in the LCC for the examined variants was also calculated (fig.1).

Table 3. LCCA for the scenarios S.1 - S.4.

\begin{tabular}{lrrrrrrrr}
\hline & \multicolumn{1}{c}{ S.1 } & \multicolumn{1}{c}{ S.2 } & & \multicolumn{1}{c}{ S.3 } & \multicolumn{2}{c}{ S.4 } \\
\hline & \multicolumn{1}{c}{ EUR } & \multicolumn{1}{c}{$\%$} & \multicolumn{1}{c}{ EUR } & \multicolumn{1}{c}{$\%$} & \multicolumn{1}{c}{ EUR } & \multicolumn{1}{c}{$\%$} & \multicolumn{1}{c}{ EUR } & $\%$ \\
\hline Acquisition costs [EUR] & 530786,52 & 78 & 530786,52 & 75 & 530786,52 & 67 & 530786,52 & 68 \\
Operational costs [EUR] & 77862,91 & 11 & 103532,20 & 15 & 195340,29 & 25 & 181388,16 & 23 \\
Maintenance costs [EUR] & 7899,70 & 1 & 7899,70 & 1 & 7899,70 & 1 & 7899,70 & 1 \\
Other costs e.g. taxes [EUR] & 63197,60 & 9 & 63197,60 & 9 & 63197,60 & 8 & 63197,60 & 8 \\
LCCA TOTAL [EUR] & $\mathbf{6 7 9 7 4 6 , 7 3}$ & & $\mathbf{7 0 5 4 1 6 , 0 1}$ & & $\mathbf{7 9 7 2 2 4 , 1 0}$ & & $\mathbf{7 8 3 2 7 1 , 9 7}$ \\
\hline
\end{tabular}

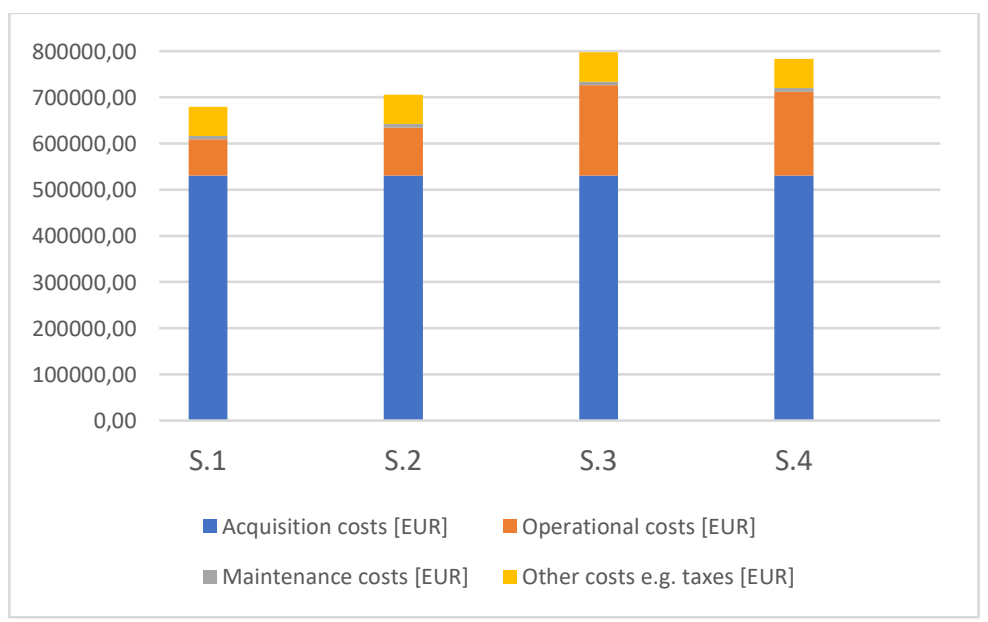

Fig.1. Total costs by categories 


\section{Discussion and conclusion}

The results of the calculations for the four variants confirmed that the use of BMS has got a positive impact on the reduction of life cycle costs. The analysed variants focused only on the costs of electricity consumption used for the pitch lighting, due to the fact that the analysis was carried out as a preliminary one, with the assumption of continuation of the deepening the LCCA issue and supporting the digital technologies in the control of the costs of construction facilities.

Based on the case of the analysed variants, the possibility to assess the impact of the BMS on life cycle costs using the LCCA calculations is presented. The analysis showed that the highest financial losses occured in variants 3 and 4 , which is a consequence of the impact of the operation phase on the sum of all life cycle costs of a facility.

The percentage increase in the life cycle costs of variants 3 and 4 compared to base variant 1 , which uses the BMS to control the pitch lighting, is $15 \%$ at the interval of 5 years. This is a significant monetary loss, especially in the context of simplification of the analysis, resulting from including only the lighting system in the calculation.

The paper presents the results of the LCCA calculations confirming the beneficial impact of using BMS in public facilities on the possibilities of the life cycle cost control of building facilities.

The method of analysis used refers to the assumptions of the ISO 15686-5:2017 standard, which provides instruments to analyse designs or existing buildings in a wide range. The standard includes both the building life cycle cost calculation methodology (LCCA) and the Whole Life Costing methodology, which allows to extend the calculation with the costs of environmental externalities and social costs. The continuation of the research described in the paper will be the analytical works extending the scope of the analysis to include further technical systems, which are part of the integrated set of systems serving the technical functions of the building with the use of the BMS and calculations covering the gradually extended range of the boundaries of the system of products (devices and systems) forming the examined technical systems.

\section{Limitations of the study}

The study, the findings of which are discussed in the article had some limitations which could affect the final results. The study, the results of which are discussed in the article had some limitations which could affect the final results.In order to obtain more ubiquitous results, similar calculations should be made for at least several similar investments. However, this would require access to design documentation for other investments, which was not possible at the stage of this study. The second major constraint is that the analysis is limited to the lighting system, and to gain a fuller understanding of the importance of BMS in controlling life cycle costs, the scope of the analysis should be extended to other systems. The limitations indicated above are related to the preliminary nature of the study carried out, which will be continued in a wider range.

\section{References}

[1] Analytical Report: Improving energy and resource efficiency, European Construction Sector Observatory, ECSO, Ref. Ares(2019)691377 - 06/02/2019, https://ec.europa.eu/docsroom/documents/33883/attachments/1/translations/en/renditions/pdf

[2] Budynki o niemal zerowym zużyciu energii (Buildings with almost zero energy consumption) Red. J. Sowa, Oficyna Wydawnicza PW, Warszawa 2017

[3] P. H. Shaikh, N. B. M. Nor, P. Nallagownden, I. Elamvazuthi \& T. Ibrahim, A review on optimized control systems for building energy and comfort management of smart sustainable buildings. Renewable and Sustainable Energy Reviews, 34, (2014), 409-429. https://doi.org/10.1016/j.rser.2014.03.027

[4] E. Curry, J. O'Donnell, E. Corry, S. Hasan, M. Keane \& S. O'Riain, Linking building data in the cloud: Integrating cross-domain building data using linked data. Advanced Engineering Informatics, 27(2), (2013), 206-219. https://doi.org/10.1016/j.aei.2012.10.003

[5] D. Clements-Croome, Sustainable intelligent buildings for people: A review. Intelligent Buildings International, 3(2), (2011), 67-86. https://doi.org/10.1080/17508975.2011.582313.

[6] A. H. Oti, E. Kurul, F. Cheung \& J. H. M. Tah, A framework for the utilization of Building Management System data in building information models for building design and operation. Automation in Construction, 72, (2016), 195-210. https://doi.org/10.1016/j.autcon.2016.08.043 
[7] G. Lilis, G. Conus, N. Asadi \& M. Kayal, Towards the next generation of intelligent building: An assessment study of current automation and future loT based systems with a proposal for transitional design. Sustainable cities and society, 28, (2017), 473-481. https://doi.org/10.1016/j.scs.2016.08.019

[8] E. M. Wetzel \& W. Y. Thabet, The use of a BIM-based framework to support safe facility management processes. Automation in Construction, 60, (2015), 12-24. https://doi.org/10.1016/j.autcon.2015.09.004

[9] D. Fisk, Cyber security, building automation, and the intelligent building. Intelligent Buildings International, 4(3), (2012), $169-181$. https://doi.org/10.1080/17508975.2012.695277

[10] C. Aghemo, J. Virgone, G. V. Fracastoro, A. Pellegrino, L. Blaso, J. Savoyat \& K. Johannes, Management and monitoring of public buildings through ICT based systems: Control rules for energy saving with lighting and HVAC services. Frontiers of Architectural Research, 2(2), (2013), 147-161. https://doi.org/10.1016/j.foar.2012.11.001

[11] L. I. L. Gonzalez, U. Großekathöfer \& O. Amft, An intervention study on automated lighting control to save energy in open space offices. In 2015 IEEE International Conference on Pervasive Computing and Communication Workshops (PerCom Workshops), (2015), 317-322. https://doi.org/10.1109/PERCOMW.2015.7134055

[12] X. Guo, D. K. Tiller, G. P. Henze \& C. E. Waters, The performance of occupancy-based lighting control systems: A review. Lighting Research \& Technology, 42(4), (2010), 415-431. https://doi.org/10.1177/1477153510376225

[13] J. Mikulik \& P. Bartkiewicz, Możliwość poprawy efektywności energetycznej inteligentnego budynku przez jego współpracę z wirtualną elektrownią. Napędy i Sterowanie, (The possibility of improving the energy efficiency of intelligent building through its cooperation with the virtual power plant), 18, 2016, 50-55.

[14] J. G. Ortega, L. Han, N. Whittacker \& N. Bowring, A machine-learning based approach to model user occupancy and activity patterns for energy saving in buildings. In 2015 Science And Information Conference (SAI), (2015), 474-482. http://doi.org/10.1109/SAl.2015.7237185

[15] A. Pellegrino, V. R. L. Verso, L. Blaso, A. Acquaviva, E. Patti \& A. Osello, Lighting control and monitoring for energy efficiency: A case study focused on the interoperability of building management systems. IEEE Transactions on Industry Applications, 52(3), (2016), 2627-2637. https://doi.org/10.1109/tia.2016.2526969

[16] Z. Nagy, F. Y. Yong, M. Frei \& A. Schlueter, Occupant centered lighting control for comfort and energy efficient building operation. Energy and Buildings, 94, (2015), 100-108. https://doi.org/10.1016/j.enbuild.2016.05.075

[17] M. Mokhtar, M. Stables, X. Liu \& J. Howe, Intelligent multi-agent system for building heat distribution control with combined gas boilers and ground source heat pump. Energy and Buildings, 62, (2013), 615-626. https://doi.org/10.1016/j.enbuild.2013.03.045

[18] S. F. Rezeka, A. H. Attia \& A. M. Saleh, Management of air-conditioning systems in residential buildings by using fuzzy logic. Alexandria Engineering Journal, 54(2), (2015), 91-98. https://doi.org/10.1016/j.aej.2015.03.014

[19] S. Sista \& A. Sista, Intelligent BMS Solution Using AI and Prognostic SPA. In Proceedings of the FISITA 2012 World Automotive Congress, (2013), 755-764. https://doi.org/10.1007/978-3-642-33741-3_4

[20] A. Kučera \& T. Pitner, Semantic BMS: Allowing usage of building automation data in facility benchmarking. Advanced Engineering Informatics, 35, (2018), 69-84, https://doi.org/10.1016/j.aei.2018.01.002

[21] Y. Zhao, T. Li, X. Zhang \& C. Zhang, Artificial intelligence-based fault detection and diagnosis methods for building energy systems: Advantages, challenges and the future. Renewable and Sustainable Energy Reviews, 109, (2019), 85-101. https://doi.org/10.3390/su12020492

[22] X. Sun, Z. Gou \& S. S. Y. Lau Cost-effectiveness of active and passive design strategies for existing building retrofits in tropical climate: Case study of a zero energy building. Journal of Cleaner Production, 183, (2018), 35-45. https://doi.org/10.1016/j.jclepro.2018.02.137

[23] L. N. Dwaikat \& K. N. Ali, Green buildings life cycle cost analysis and life cycle budget development: Practical applications. Journal of Building Engineering, 18, (2018), 303-311. https://doi.org/10.1016/j.jobe.2018.03.015

[24] M. U. Khalid, M. K. Bashir \& D. Newport, Development of a building information modelling (BIM)-based real-time data integration system using a building management system (BMS). In Building Information Modelling, Building Performance, Design and Smart Construction, (2017), 93-104. https://doi.org/10.1007/978-3-319-50346-2_7

[25] H. B. Cavka, S. Staub-French \& E. A. Poirier, Developing owner information requirements for BIM-enabled project delivery and asset management. Automation in construction, 83, (2017), 169-183. https:// doi.org/10.1016/j.autcon.2017.08.006

[26] A. GhaffarianHoseini, T. Zhang, O. Nwadigo, N. Naismith, J. Tookey \& K. Raahemifar, Application of nD BIM Integrated Knowledgebased Building Management System (BIM-IKBMS) for inspecting post-construction energy efficiency. Renewable and Sustainable Energy Reviews, 72, (2017), 935-949. https://doi.org/10.1016/j.rser.2016.12.061

[27] R. Eadie, M. Browne, H. Odeyinka, C. McKeown \& S. McNiff, BIM implementation throughout the UK construction project lifecycle: An analysis. Automation in construction, 36, (2013), 145-151. https://doi.org/10.1016/j.autcon.2013.09.0

[28] M. Meslec, S. Ashworth \& C. Druhmann, Integrating life cycle sustainability analysis with BIM. In 17th EuroFM Research Symposium, (2018), 96-108. https://digitalcollection.zhaw.ch/handle/11475/15228

[29] W. K. Biswas, Carbon footprint and embodied energy consumption assessment of building construction works in Western Australia. International Journal of Sustainable Built Environment, 3(2), (2014), 179-186. https://doi.org/10.1016/j.ijsbe.2014.11.004

[30] B.H. Goh \& Y. Sun, The development of life-cycle costing for buildings, Building Research \& Information, 44:3, (2016), 319-333. https://doi.org/10.1080/09613218.2014.993566 